\title{
Mobilizing Global Business for a Healthier World
}

\author{
Maria L. Nathan \\ School of Business and Economics, Lynchburg College, Lynchburg, Virginia, U.S.A. \\ E-mail: Nathan@lynchburg.edu
}

Received: May 06, 2016 Accepted: May 11, $2016 \quad$ Published: August 28, 2016

doi:10.5296/csbm.v3i2.9425 URL: http://dx.doi.org/10.5296/csbm.v3i2.9425

\begin{abstract}
GBCHealth (formerly the Global Business Coalition) has sought to apply the unique skills and expertise of the for profit world in the fight against HIV/AIDS, Malaria, TB, and other global health problems. Founded in 2001, GBCHealth is dedicated to "mobilizing business for a healthier world." The alliance has rapidly grown from 17 to 220-plus international companies headquartered in over 30 different countries and representing all parts of the world; different workforces, industries, and geographical regions. A sharper focus is given to this analysis of GBCHealth's within and cross-sector initiatives and accomplishments with use of an inter-organizational theory-based framework. This commitment by GBCHealth and alliance partners is a hopeful act of social responsibility that represents awareness of correlated fates as well as good business sense.
\end{abstract}

Keywords: Global Health Alliances, Global Business Coalition (GBCHealth), Social Responsibility 


\section{Introduction}

Long considered a medical and social ill, HIV/AIDS has clearly moved into the workplace and become one of the most urgent business issues facing companies big and small today (Brooks, Martin and Veniegas, 2010; Kessler, Ames, Hymel, Loeppke, McKenas, Richling, Stang, \& Ustun, 2004; Burton, 2010; Wolf, 2010; Nielsen, Bery, \& Mistry, 2004; Rosen, Simon, Vincent, MacLeod, Fox, \& Thea, 2003). The first known case of HIV/AIDS in the United State was in 1981. Currently it is estimated that 1.2 million people in the United States alone are estimated as infected with HIV (1 in 7 are unaware of their infection), and 658,507 have already died (AIDS.gov, 2015). By the end of 2013, 35 million people around the world were living with HIV/AIDS (WHO, 2015), more than 78 million people have been affected by the HIV virus, and about 39 million people have died of HIV/AIDS.

It has been estimated that the global workforce has lost 28 million people to AIDS since the beginning of the pandemic (UNAIDS, 2010). Direct costs include recruitment and training of replacement workers, insurance premiums, accidents due to ill workers and inexperienced replacement workers, costs of litigation over benefits in addition to other issues. Indirect costs include reduced on the job productivity, reduced productivity due to employee absences, supervisor lost time in dealing with productivity losses, vacancies until replacements are hired, and reduced productivity while replacement workers learn jobs. Other indirect costs include senior management lost time, production disruptions, depressed morale, loss of experienced workers, and deterioration of labor relations (Rosen et al., 2003).

In developing countries such as South Africa, Russia, China, India, and Brazil, where the disease has hit hardest, the impact on the organizational bottom line is magnified. Companies that do business in Africa suffer the impact of HIV/AIDS on their staff, while their entire customer bases are being affected as well. It has not been uncommon for companies in some parts of the African continent to hire two employees for every position, since the chances have been so great that one or more of them would come down with symptoms of the disease and become unable to work (Caminiti, 2003).

The purpose of this research is to explore the initiatives and accomplishments of a large global coalition of businesses that has come together in recognition of an increasingly interdependent world, an integral relationship between employee health and organizational performance, an organizational need for cost effective solutions, and as these organizations realize their unique power to effect a more strategic collaboration both within the private sector and across to other sectors. This particular coalition, GBCHealth, is composed of organizations that have joined together to resolve a social problem that could not be solved by these organizations acting alone.

An inter-organizational theory and development conceptual framework (cf.: Cummings, 1984; Nathan \& Cummings, 1991; Boje, 1997; Harris, Provan, Johnson, \& Leischow, 2012; Pesamaa, 2007) will be used to guide and further focus this discussion of large-scale change through international cross-sector collaboration. This underlying theoretical framework will first be developed before returning to an in-depth case exploration of world-wide social change through business initiated acts of social responsibility. 


\section{A Framework for Collaboration}

Trans-organization development is the planned change in the collective relationships among a variety of stakeholders to accomplish something beyond the capability of any single organization or individual (Nathan \& Cummings, 1991). This model can be used to help focus upon key variables and relationships that have been identified by researchers as instrumental in the accomplishment of desired inter-organizational collective outcomes (cf.: Cummings, 1984; Nathan \& Cummings, 1991).

\section{ENVIRONMENT}

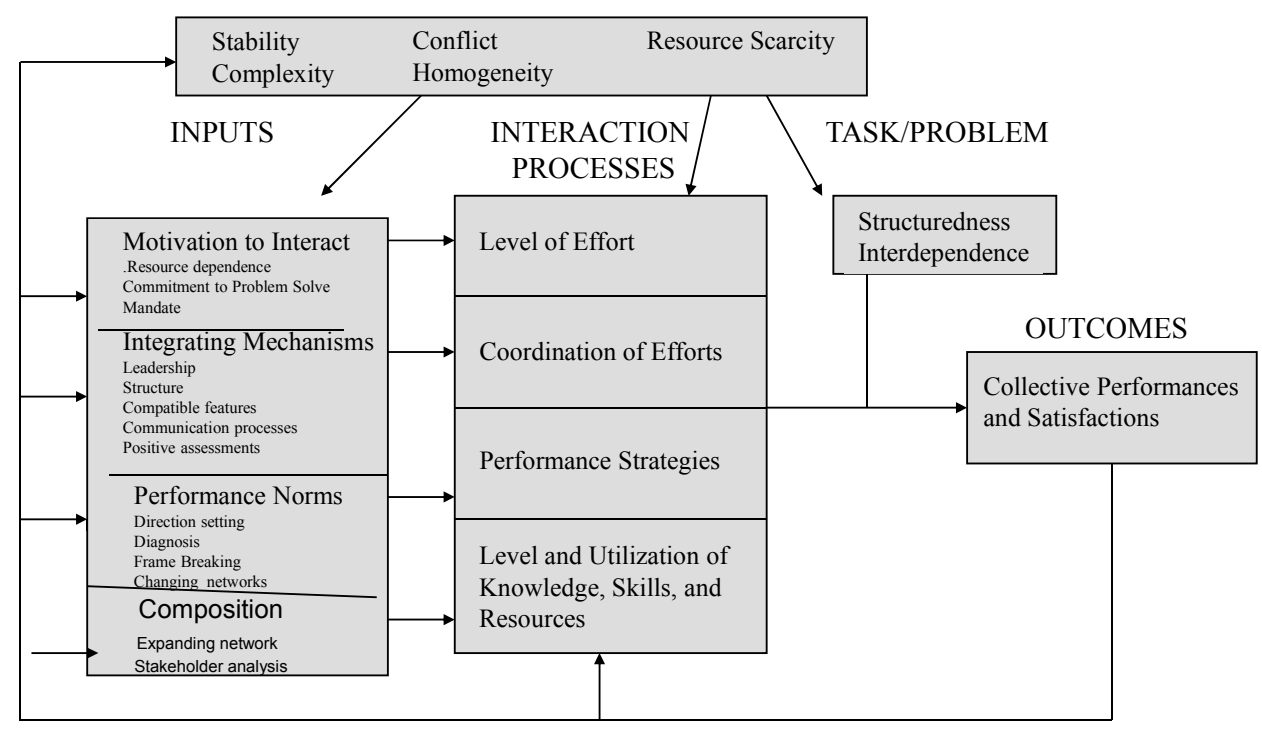

Figure 1. Input-process-outcome model of trans-organizational system functioning

This system's model explores the inter-relationships within an environment and among key inputs, interaction processes, the task itself, and collective outcomes.

The collective consciousness of correlated fates takes root as clear motivation to interact is recognized, integration mechanisms to begin the process are identified, performance norms are established, and composition of the larger field of concerned agents is identified.

Interaction Processes: Four interaction processes are central to the conversion of inputs into outcomes: (1) level of effort, (2) coordination of effort, (3) performance strategies, and (4) level and utilization of knowledge, skills, and abilities. Briefly, level of effort addresses how motivation to collaborate can be engendered and sustained among organizations. Coordination of effort addresses how these organizations can come to work together smoothly. Performance strategies address the challenge of getting resources to where they are most needed. Finally, level and utilization of knowledge, skills, and resources explores how collaborators can ensure that that they are using what they have as efficiently and effectively as possible. 
These four interaction processes - effort level, coordination, strategies for performance, and knowledge, skill, and resource level and utilization, are each affected by a distinct set of input activities (refer to Figure 1). For example, how effectively efforts are coordinated depends upon the following inputs: quality of leadership, structure, compatible features among the collaborating organizations. Thus, inputs affect quality of interaction toward the outcome-collective performance/satisfactions. The outcomes of collaborative activity are further mediated by the external environment and the particular type of task or problem.

This model, based in inter-organizational theory/development and its literatures, details the key variables and relationships for trans-organizational collaborative activity. The model is also intended for actual interventions in which a set of collaborators are helped to improve their functioning (Cummings, 1984) and therefore has a whole additional utility beyond achieving clearer vision of a complex set of collaborative activities of the GBC. This model will underpin the discussion of the GBC and its activities for both of these above reasons.

\section{GBCHealth and its Commitment to Global Health}

GBCHealth members believe that big business has the infrastructure and influence to educate the greatest number of people about HIV/AIDS and related health threats in the most efficient way. A key global health figure, Richard Holbrook, has advised; "Businesses have an obligation to confront illnesses such as AIDS in the workplace and find ways to deal with them" (Caminiti, 2003, S2).

Leaders from those companies with operations in regions heavily affected by HIV/AIDS and closely co-occurring TB and Malaria support the implementation of comprehensive workplace programs (such as non-discrimination, prevention, education, access to voluntary counseling and testing, as well as care, support, and treatment) since the late 1990's.

Founded in 2001, GBCHealth is a New York City-based alliance with regional offices in Beijing, Geneva, Johannesburg, Nairobi, and Paris. Among the GBC membership are included such globally prominent giants as Bayer (Germany), Coca-Cola (U.S.), Daimler-Chrysler (Germany), DeBeers Group (South Africa), DHL Worldwide (Belgium), GM (U.S.), HSBC (UK)Time Warner (USA), Heineken (Netherlands), Merck (U.S.), National Basketball Association (U.S.), SRF, Ltd. (India), Shanghai Desano Pharmaceutics Holding Co., Ltd. (China), and Sumitomo Chemical (Japan).

In July 2011, upon the 10th anniversary of the GBC's founding, GBC officers announced a name and scope change. The GBC became GBCHealth with a tagline "Mobilizing Business for a Healthier World." This strategic move was an expansive, natural progression in GBC member intentions. The change over time has been a function of the membership's growing understanding of global health care and its activities to aid those in developing economies. Over time it has become clear to the coalition that the GBC needed to expand to include TB and Malaria because the two diseases were so prevalent in countries where HIV/AIDS was also most prevalent-even working as sources of cross-infection and root causes of compromised immune defenses.

The GBC recognized a need to expand scope still further because HIV/AIDS/TB/Malaria 
were not the only health care concerns in developing economies. It was recognized that a complete health care infra-structure within these countries was required. The infrastructure needed to also include facilities, personnel, equipment distribution, supply chains, patient history tracking, and cross-functional support for other health maladies including TB and Malaria. GBC membership considered that citizens in developing economies should be able to receive quality health care even if they hadn't contracted the diseases which the GBC had originally targeted (GBCHealth, 2011).

The GBCHealth mission is to "leverage the resources of the business community for positive impact on global health challenges." Their vision is that they are "a global business community that is fully contributing assets, skills, influence and reach to making a healthier world for employees, their families, and their communities."

The GBC sought to harness the individual and collective power of the world's top corporations to fight for global health at the local, national, and international levels by using the business sector's unique skills and expertise. For example, media companies have carried public service announcements; some businesses have leveraged advertising and branding skills to advance HIV/AIDS prevention and behavior change messages through cause-related marketing campaigns; some companies have used logistics expertise to help optimize the flow of HIV/AIDS medicine and materials around the world (GBCHealth, 2011).

GBC members recommend that global health should be seen as a core business issue - central to everyday thinking - for every company, particularly those with interests in seriously affected countries. Suggests John Tedstrom, GBC's executive director, the evolution of business' role as an active partner in the fight has reached a point at which a major, world-changing breakthrough is possible (CSRWire, 2008).

The GBCHealth accomplishes its mission by supporting member companies through the following efforts:

- Convening and connecting businesses, governments, multilaterals and civil society for the purpose of knowledge and ideas a sharing on global health.

- Driving the creation of high-impact partnerships and collective actions.

- Providing recognition and visibility to members for the global health work they support.

- Championing best practices in business engagement on health.

- Representing business in key global health settings.

- and providing advisory services and guidance to individual member companies, as needed (GBCHealth, 2015).

The GBC's origins and purposes having been detailed, the aforementioned inter-organizational conceptual framework will be adapted for a more in-depth study of GBCHealth. Each of the four key interaction processes will be detailed along with their corresponding inputs: 


\section{GBCHealth Interaction Processes and Corresponding Inputs}

(1) Level of Effort: This variable addresses how motivation to collaborate can be engendered and sustained among organizations as the global health campaign continues. Among the initiatives to increase effort are included resource dependence among involved parties and their collective commitment to problem solving (Cummings, 1984). (See Figure 1.)

Resource dependence: When organizations realize that they need one another in order to accomplish desired ends, they will work harder at working together. GBCHealth has sought to build consciousness of correlated fates as a means for leaders and their organizations to search for ways to contribute. They have recruited many organizational members over time (not just the 230 plus business members, but additional partnerships with representatives from many and varied industries, national governments, and the nonprofit world).

Efforts to build consciousness of correlated fates are critical as a means of gaining peoples' attention and getting them to remember, to understand, to care, and to act. When destinies are seen as inextricably yoked, the plight of HIV/AIDS and other health threats inspire people to become involved and see how they can make remedy.

To this end, one device that has been used by the GBCHealth has been the Red Ribbon Campaign - the red ribbon being the international symbol of HIV/AIDS awareness. The National AIDS Virtual Red Ribbon campaign was originated to raise awareness that HIVAIDS is increasing across the world. Organizations, for example, can have the Virtual Red Ribbon on their web sits and link visitors to www.worldAIDSday.org. Among the many examples of GBC member intense effort is an employee-based initiative among United Kingdom GBCHealth employer organizations has been the "Your Finest Hour Campaign", involving over 40 participating companies and is designed to educate employees and customers about HIV/AIDS. The campaign asks employees to donate one hour of their annual salary to benefit projects that target youth in South Africa.

Significantly, GBCHealth's global outreach is extensive given the fact that HIV/AIDS is a problem shared by all across the globe. Yet they acknowledge that many more affected companies are not yet represented in the GBCHealth efforts. For example, until quite recently there were no GBCHealth members among Japanese companies.

The very purpose of GBCHealth is centered in the fact of global resource dependence-what business has that other sectors need and what other sectors may have that GBCHealth needs if they are to have an impact (e.g., political power).

Commitment to Problem Solving: This suggests a future orientation in which partners seek to build a relationship that can weather unanticipated problems. A high level of commitment provides the context in which both parties can achieve individual and joint goals without raising the specter of opportunistic behavior (Cummings, 1984).

The more deeply the membership feels a commitment to this problem which they share, the more motivation they will experience. This is critical especially because GBCHealth is, after all, a loosely structured coalition of very busy individuals for whom GBCHealth is not 
primary employment.

Efforts to stimulate and sustain motivation also include emotional appeals through human interest stories/pictures and personalized message to get people to recognize fates yoked as they fight against a shared enemy. For example, a member firm of GBCHealth, Getty Images, provides high quality, compelling pictures of people whose lives had been touched by AIDS and other deadly illnesses. These images have been viewed by publics around the world. Especially emotionally charged were pictures of AIDS orphans (16.6 million children have lost one or both parents by the year 2009).

Another device that has been used by GBCHealth to this end has been the recruitment of individuals with high referent power with AIDS audiences who are capable of igniting passion for the cause. For example, at the Barcelona AIDS Conference in 2002, President Clinton addressed the 4,000 attendees encouraging them not to be discouraged with how much is yet to be done. He pointed out that a number of prominent political figures have opened their eyes to the severity of the epidemic and have committed themselves to action as a result of the work of HIV/AIDS cause champions. It was observed that many delegates who attended the meeting carried away feelings of hope and solidarity after sharing a week with like-minded colleagues in Barcelona.

To sustain motivation, GBCHealth has also found means to reward their constituencies for global health program accomplishments. For example, six companies that conceived and executed creative and effective HIV/AIDS programs in workplace, community, core competency, national action, testing and counseling, and leadership, were awarded Business Excellence Awards at one of the annual GBCHealth annual galas. In 2014, GBCHealth recognized Laerdal Global Health's exceptional contribution to the health of hundreds of thousands of mothers and babies around the developing world (GBCHealth, 2014).

The above then are all measures for sparking and sustaining motivation to continue the fight for a healthier, disease-free world. Next, means by which GBCHealth fuels the coordination of effort among members and with communities and networks is addressed.

(2) Coordination of Effort: GBCHealth and its partners represent a large and fast growing number of agents working on the shared cause. Coordination of effort addresses how these organizations can come to work together smoothly. Among the inputs that most affect coordination of effort (as shown in Figure 1) are: leadership, structure; compatible features, communication processes, and positive assessments (Cummings, 1984).

Leadership is "the inspiration and mobilization of others to undertake collective action in pursuit of the common good" (Bryson \& Crosby, 1992, p. 31). GBCHealth and its membership organizations' leaders help constituents by framing and referencing a public problem that spills beyond national and international boundaries, championing new and improved ideas for dealing with these problems as they pay careful attention to the design of formal and informal forums. They can gather evidence and present it in attention-getting ways (Crosby, 1999).

Leaders weave together their understanding of context, social needs, the interpretation of 
problems and promising solutions into visions that can help others to develop and sense what they have in common with each other (Crosby, 1999, p. 113). "The ability to understand the problem, make it real, explore and analyze the set of possible solutions, and create shared vision can be magnified by convening forums in which many people with partial knowledge of the problem come together to share results of formal or informal research" (Crosby, 1999, p. 119).

GBCHealth leaders have tackled the stigma and discrimination over the past several dozen years. These leaders within their own companies and in their inter-organizational activities have worked as advocates with government leaders and are critical tools in forcing their societies to address AIDS openly and honestly. For example, GBCHealth member, Chris Kirubi, Chairman of Haco Industries of Kenya took an HIV test on prime-time national television in order to help break the taboos surrounding the disease and to encourage the general public to seek testing as well (Global Business Coalition, 2006). GBC member company, American Express, received the GBC Leadership Award as a founding partner of the groundbreaking RED campaign. Debuted in the UK, this card has served to raise awareness about the fight against HIV/AIDS in Africa. American Express RED promises consumers that for every eligible pound spent, a minimum $1 \%$ would be earmarked for the Global Fund to Fight AIDS, Tuberculosis and Malaria.

Structure: Structure is as the scaffolding upon which GBCHealth members perch while seeking to enact the varied strategies for accomplishing shared desired ends. Structural arrangements have included breakdown of membership into varied groups such as working groups and industry groups. Beyond the formal boundaries of GBCHealth, expert teams have assisted member companies in the design and development of specialized programs that leverage a company's assets and business skills to tailor an individual response to the crisis.

Bridging organizations are organizations whose primary role involves the linking of other organizations and individuals without incorporating those other actors. The bridging organization's primary purpose is the connections of other organizations and individuals so that they may work together (Brown, 1991). GBCHealth becomes more and more central to the HIV/AIDS and global health cause as it acquires richer and richer networks of involved parties. Thinking of the GBCHealth as a bridge in service between other involved parties also facilitates their ability to use their central location to unique and positive ends.

Compatible features: Considerations such as domain similarity and goal compatibility have been found to enhance the effectiveness of coalitions. In general, partnerships must be attuned to fundamental compatibility between partner values, culture, and other fundamentals. It is easier for the partners to coordinate their operations when they are similar on these basics. For example, global companies may have a natural affinity given their global scope; for profit organizations would share a fundamental concern for profitability.

GBCHealth demonstrates this awareness in the way in which they have clustered their Working Groups that use extended case analytic treatment of various HIV/AIDS programs clustered by industry, issue, and key HIV/AIDS relevant variables. 
Communication processes: Each person in any of the above GBCHealth-related groups is connected to professional groups, other voluntary organizations, and political networks through teleconferences, newsletters, journals, web pages, global conferences. Personal connections help in gaining access to existing media forums. For example, the International AIDS Society, an affiliate of GBCHealth, circulates a newsletter to physicians and researchers involved in the treatment and study of AIDS, including infectious disease specialists, public health officials, pathologists, immunologists, and oncologists. Fast-track procedures for priority papers allow colleagues' important work to be seen in the shortest time possible. GBCHealth and many of its partners are globally-based. Without effective inter-organizational communications (and inter-national communication), the effectiveness of inter-organizational initiatives could be damaged (Griffith \& Harvey, 2001). For example, many of the Working Groups communicate via telecommunication resources.

Cultural understanding enables GBCHealth members to engage in appropriate and meaningful interactions with those from divergent national and organizational cultures, suggesting that GBCHealth members must recognize this and become sensitized to possible differences among parties from diverse cultures that are working together.

In sum, the above set of activities all serve to develop a shared appreciation of the global health threat and provides incentive to expend effort as members work together as rapidly, meaningfully, and effectively as possible. The next of the four integrating mechanisms entails the use of strategies by which the task of global health awareness, illness prevention, treatment, and recovery are made possible.

(3) Performance Strategies: The challenge has been to get resources to where they are most needed. Again according to the conceptual model diagrammed in Figure 1, among the input activities to which GBCHealth should be attentive are included: (a) direction setting, (b) performance norms, (c) diagnosis, and (d) frame breaking of collective definitions (Cummings, 1984; Nathan \& Cummings, 1991).

Direction setting: GBCHealth has given clear direction to its membership and other collaborators through their mission, objectives, how they reward their members (e.g., Excellence Awards) and what they measure. One might argue that a key core competence of GBCHealth as a federation of for profits has been its strategic awareness. They were among the first in business to recognize the serious implications of HIV/AIDS for global business, to recognize that the solution to the problem was broad based inter-organizational collaboration, and to insist that the coalition should be founded upon for profit core competencies.

Performance norms: Norms are a behavioral subset of a culture and are defined as the explicit or implied "rules" of behavior in the group - who can do what and when. Arguably, the coalition requires more clearly articulated norms for behavior even more than the single organization (due to its under-organized and fragile nature). A code of conduct in particular guides the behaviors of leadership and helps them to protect legitimacy while striving to reach desired objectives. It may also serve to harmonize multi-sector responses, donor activities, monitoring, and evaluations so that countries can be successful in their national response (UNAIDS, 2004). 
GBCHealth's code of conduct enables it to demonstrate its accountability, openness to public scrutiny, adherence to acceptable ethical standards of behavior, and commitment to a democratic approach to members and supporters. GBCHealth performance norms are inherent to the organizational best practices information that GBCHealth makes available for use of its membership. They are also inherent to the highly publicized excellence awards that are distributed each year.

Diagnosis: Getting resources to where they are most needed also requires that the attendant problems have been carefully diagnosed. For example, there has been an urgent need to scale up access to HIV/AIDS treatment through anti-retroviral (ARV) therapy. GBCHealth endorsed free HIV/AIDS testing in the workplace only to find that the problem wasn't access, the problem was that employees were concerned about privacy and job loss in the workplace and so testing rates were quite low. In recent years, GBCHealth surveys its membership as a means of assessing progress they have made toward the goals they have established. They have used these results to focus their attention to the key HIV/AIDS problems such as affordability of anti-retroviral therapy in the less developed countries ((the World Health Organization, 2015; Avert.com, 2012).

Frame-breaking of collective definitions: Frames are defined as ideologies that are in dialectic contest, resisting each other, competing, and refusing to synthesize (Boje \& Wolfe, 1988). Collective definitions give legitimacy and meaning to actions, but once constructed, are highly resistant to change. For example, common knowledge among global corporations working in Africa is that there remain African governments that still do not acknowledge the link between sex and HIV. Not surprisingly, many African citizens do not see this link either. The fourth and last interaction process is next detailed.

(4) Level and Utilization of Knowledge, Skills and Resources: A key reason for trans-organizational formation is the ability to leverage the partners' respective competencies. Thus, the collective must be composed of those who possess knowledge and skill to desired ends. Stakeholder analysis involves identifying and selectively recruiting organizations that are affected by a shared problem domain and who have a stake in the solution (Hood, Logsdon, Thompson, \& Kenner, 1993). This model is used to assure that a partnership or network is composed of organizations with task-relevant skills, knowledge, and resources. This approach may also be used to find under-utilized agents who may lend help to the cause and assess stakeholders' perceived inter-dependence. Many varied approaches are possible including a reputation approach that asks the community to suggest persons, opinion leadership methods that identifies stakeholders on the basis of their leverage or influence in relation to the task.

What is significant in the case of GBCHealth is that they acknowledge a great number of stakeholders in their work. This recognition of "correlated fates" has enabled them to search broadly for other stakeholders with whom they can work, including GBCHealth member organization employees, communities; industry associations, industries, government agencies at various levels, non-governmental organizations, and others. It has also permitted them to build capacity and develop infra-structure. Capacity building increases the knowledge and 
skills of partner agencies, communities and organizations. GBCHealth does this in particular through its use of experts as they help to develop programs in member organizations.

As GBCHealth hones their expert skills, they must consider how they can most effectively make this information available to others. For example, they have created an Interactive Company Case Studies Database designed for company managers who wish to establish their own workplace programs. The cases are organized by company, intervention, industry, region, and workforce size. Some of this information is available on their website; other information is available only to GBCHealth members.

GBCHealth has also published a number of books, magazines, and reports such as Business \& AIDS Magazine, Outstanding Business Action on HIV/AIDS Case Studies, and A Practical Guide for Business Managers.

Expanding Resource Model: A smaller core group of organizations expands membership as additional stakeholders and resource groups are identified and recruited. In this way, more useful organizations and resources are brought to bear on shared problems (Cummings, 1984).

This is precisely what GBCHealth has done with their teleconference linked Working Groups of up to 10- member companies organized by region, sector, or issue. Since 2004, GBCHealth has been organizing these issue-based working groups to pursue key areas of shared interest. Sharing goals of shared best practices, collaboration and innovation in the cause of global health, these groups provide a forum for GBCHealth members to discuss policy issues that affect their sector. Also, education of senior policy makers on issues of concern to corporations is made possible. For example, there is a Biotechnology Working Group and a Fashion and Apparel Working Group. GBCHealth also has a very broad network of partnerships with HIV/AIDS and other development organizations, business associations and international organizations all over the world. In particular, GBCHealth has established a Civil Society Advisory Council with global health experts from different parts of the world.

GBCHealth has also been actively establishing partnerships with other cause-related non-governmental organizations (NGO's), government agencies, community organizations, and nonprofits. This activity is vital to spreading the word, but also as a form of opportunity for all involved to learn from others on various aspects of this complex crisis.

The business sector has a significant opportunity to advance community access to testing services through existing networks, relevant products, and marketing expertise. They are also able to develop innovative products, and donations, and are able to distribute HIV test kits and diagnostics. Organizations can offer their existing infrastructures in the form of clinics, trained professionals, lab facilities, distribution networks, support, testing, and service delivery. The "Keep a Child Alive" campaign, for example, is dedicated to providing life-saving medicine to children and families with HIV/AIDS. This campaign offers community members the opportunity to pay for treatment and help to save a child's life.

Collective Outcomes: Referring back to Figure 1, collective outcomes is an especially significant item in this model of organizations working in collaboration. It is the collective's 
bottom line - did important variables change as a result of their collaboration. It is also significant because this is a coalition of for-profit organizations for whom the bottom line is of signal importance. If they did not engage in measurement on key variables over time, then it might be questioned if these for profits truly gave from among their core competencies.

In fact, GBCHealth has been surveying their membership as a means of learning about changes that have happened over time. The State of Business and HIV/AIDS (2006) is a GBCHealth survey that provided a baseline from which to evaluate the response made by business in the global health cause. Their baseline report captured critical information on corporate responses to HIV/AIDS across criteria, regions, and industries. It is a report on what business has accomplished thus far. Their baseline report surveyed 75 GBC member companies from across 17 industries. This report shared statistics on prevention programs, peer educators programs, and community prevention programs. For example, in high HIV prevalence parts of Africa, more than 70 percent of companies surveyed are fully subsidizing staff access to HIV treatment. Globally, 36 percent of surveyed companies are fully subsidizing treatment for direction of employees and 45 percent are providing access to treatment for all dependents (Turnbull, Parry, Gravestock, Guilford, Clayton, Bery, Gorre, Lee, Mistry, \& Tanguy, 2006). With foresight, GBCHealth has also used the report to highlight areas where much improvement is still needed, including the development of strategies to work closely with suppliers, increasing businesses advocacy role in emerging markets, and partnerships with NGOs, community, and local governments.

The strength of this approach taken in the study of business social responsibility through inter-organizational collaboration is that as a case analysis it helps us to recognize more fully the sheer necessity for and challenges of inter-organizational collaboration. It also encourages the business sector to use core competencies to take on additional daunting (shared) social challenges at which they may excel. The use of a theory-based and integrative conceptual model also ensures that there is a continuity of current work with research that has been conducted to date. Limitations include concerns for generalizability from this case to other inter-organizational collaborative pursuits (Leonard-Barton, 1990).

GBCHealth is heralded as a powerful exemplar for business (collaborative) social responsibility. The alliance seems quite well structured with outstanding leadership within its core New York City office, not to mention the leadership that is diffuse across the globe. As time passes, a fuller picture of this trans-organization (with already considerable longevity for an inter-organizational enterprise) can be developed.

\section{Conclusion/Discussion}

In an Open Forum some years back Colin Powell asked how partnerships could be put together in a more effective way so that the United States would be able to more effectively lead the global fight against HIV/AIDS. Global organizations have also come to find that their own problems are "correlated" with other organizations' problems, and that these shared problems need to be addressed through joint activity (Austin, 2000; Gray, 1989; Nathan \& Mitroff, 1991; Osborn \& Hagedoorn, 1997). 
However, though these organizations may be experienced in planning competitive strategies, they may not be familiar with the formal planning required for inter-organizational cooperative strategy (Gray, 1989; Nathan \& Mitroff, 1991; Crosby, 1999). U.S. based for profit strategic alliances have experienced a quite high failure rate $(70 \%)$ (Hambrick, Li, Xin, \& Tsui, 2001) while cross-sector collaborations have experienced even more difficulties than intra-sector linkages (Hood, Logsdon, Thompson, \& Kenner, 1993; Nathan \& Mitroff, 1991; Post \& Waddock, 1989). Thus, there is a need for special attention devoted to the inter-organizational management and development for shared inter-organizational crises such as global HIV/AIDS.

A common element among all crises is that they can harm organizational stakeholders, including employees, shareholders, and surrounding communities (Mitroff, Pearson, \& Harrington, 1996). Their impact can reach beyond geographic boundaries and affect remote stakeholders including future generations (as in the estimated 11-12 million AIDS orphans currently found in Sub-Saharan Africa alone) (UNAIDS, 2015).

Crises such as HIV/AIDS inevitably raise questions regarding social responsibility which include not just economic, legal, but ethical responsibility as well (Steiner \& Steiner, 2003). Proponents of social responsibility suggest that what is required is that organizations do all that is humanly possible to avert crises that are limited to their stakeholders and to minimize losses to stakeholders (Ozcelik, Langton, \& Aldrich, 2008).

GBCHealth's Richard Holbrooke has preached the importance of corporate involvement, believing that we've just scratched the surface on this corporate social responsibility issue. GBCHealth and its larger trans-organizational field of crisis managers are in a race against time. GBCHealth has been working for over one dozen years so far. Much work has been done to choose GBCHealth leadership and to train these leaders to act as force multipliers for global social change in the employment setting.

Business brings with it qualities that can turn the tide of the epidemic. The private sector's special skills include entrepreneurial spirit and problem solving expertise. Companies' core skills can be leveraged to positively impact the epidemic. Efficiency of operations, overcoming obstacles, responsibility for achieving concrete outcomes, and accurately gauging perceptions and human behavior all help business to thrive and are prerequisites for success in battling the pandemic locally, nationally, and internationally (Nattrass et al., 2004). Says GBCHealth's Holbrooke: "Businesses have an obligation to confront AIDS in the workplace and find ways to deal with it" (Caminiti, 2003).

Partnerships between business, government and civil society can extend the reach of prevention and treatment programs through shared infrastructure and human resources between sectors (GBCHealth, 2014). Progress in this area shows the potential for business to advance a country's response to HIV/AIDS and mitigate macroeconomic impacts across communities. Nationally and internationally, business can lobby governments for urgent resource mobilization, investment in collaborative campaigns, engage in collective bargaining for low cost HIV/AIDS drugs and diagnostics and more. 
Addressing HIV/AIDS is relatively new for many company managers. Business leaders have admitted that partnerships with governments, community based organizations and unions have been critical for supporting their HIV/AIDS/global health response. The inclusion of people living with HIV/AIDS and other cause-related illnesses as labor representatives and community members has helped as well.

Business has only done a tiny percentage of what it could be doing to address HIV/AIDS and other global health issues. According to one survey of nearly 8,000 firms conducted by the World Economic Forum, 47\% felt the epidemic is having or will have some pact on their business, yet only $3 \%$ of these firms are satisfied with their companies' response to date (Bloom, Bloom, Steven, \& Weston, 2003).

Until relatively recently, most organizations in the business sector assigned responsibility for global health to governments, activists, or the public health community. The need for collective activity among the sectors is urgent. Many such partnerships have been proliferating over the past decade and only more will be founded in the future. Furthermore, these partnerships will provide a base for addressing the next generation of issues... and the critical, enduring challenges... in the fight against HIV/AIDS and other global health issues (Fisher-Thompson, 2002; Lawrence, 2002).

What remains to be more fully formulated is a systematic means for developing and assessing the activities of these organizations. This research report opens up this partnership to private and public managers' and researchers' scrutiny. Additional frameworks and tools offered here should make it easier for both private and public managers to understand and use these frequently under-developed systems more effectively (Nathan \& Kovoor-Misra, 2002).

This paper explores the collective initiatives of global business and their expanding set of partners that more and more act toward the social change they wish to see in the world. Global organizations such as the GBCHealth membership continue to recruit other organizations to become involved and share unique capabilities, agitate for change both within and outside of their organizations, promote awareness, engage employees, test for global health perils, train their managers in human resource policies/practices, and more; fundraise for global health around the world; advocate for GBCHealth's policies around the world; and provide needed financial and technical resources. More and more this vision of global health is held by business, government, and nonprofit collaborators who work to protect and support a humanity that is troubled with serious health threats.

\section{References}

Austin, J. E. (2000). Strategic collaboration between nonprofits and business. Nonprofit Voluntary Sector Quarterly, 29(1), 69-97. http://dx.doi.org/10.1177/089976400773746346

Avert.com (2012). [Online] Available: www.avert.com

Bloom, D., Bloom, L. R., Steven, D., \& Weston, M. (2003). Business and HIV/AIDS: Who me? World Economic Forum.

Boje, D. M. (1997). Transorganization development and the death of organization 
development.

Boje, D. M., \& Wolfe, T. J. (1988). "Trans-organization development: Contributions to theory and practice. In H. J. Leavitt, L. R. Pondy, \& D. M. Boje (Eds.), Readings in Managerial Psychology (4th Ed. pp. 733-751). Chicago: University of Chicago Press.

Brooks, R. A., Martin, D. U. J., Ortiz, D. J., \& Veniegas, R. C. (2010). Perceived barriers to employment among persons living with HIV/AIDS. AIDS Care: Psychological and $\begin{array}{lllll}\text { Socio-Medical Aspects } \quad \text { of } & \text { 756-766. }\end{array}$ http://dx.doi.org/10.1080/09540120412331269594

Brown, L. D. (1991). Bridging organizations and sustainable development. Human Relations, 44, 807-831. http://dx.doi.org/10.1177/001872679104400804

Bryson, J. M., \& Crosby, B. C. (1992). Leadership for the Common Good: Tackling Public Problems in a Shared-Power World. San Francisco: Jossey-Bass.

Burton, J. (2010). WHO health workplace framework and model: Background and supporting literature and practices. World Health Organization.

Caminiti, S. (2003). A prophet of hope. Business Week, S2-S7.

Crosby, B. C. (1999). Leadership for Global Citizenship: Building Transnational Community. San Francisco: Sage Publications.

CSRWire.com (2008). Package of business actions to change the complexion of the fight against HIV/AIDS; TB, and Malaria. [Online] Available: http://www.csrwire.compress_releases?20145-Package-of-Business-Actions

Cummings, T. G. (1984). Trans-organizational development. In B. Staw \& L. L. Cummings (eds.), Research in Organizational Behavior, 6. Greenwich, CT: JAI Press.

DeCock, C. (1999). Organization change and discourse, hegemony, resistance and reconstitution. Management, 1(1), 1-22.

Fan, H. Y., Conner, R. F., \& Villarreal, L. P. (2004). AIDS: Science and Society. Massachusetts: Jones and Bartlett Publishers.

Fisher-Thompson, J. (2002) HHS secretary lauds public private partnerships battling AIDS in Africa. [Online] Available: http://www.usinfo.state.gov

Global Business Coalition on HIV/AIDS (2006). Why is HIV/AIDS a business issue? [Online] Available: www.businessfightsaids.org

GBCHealth (2015). GBCHealth Mission: To leverage the resources of the Business community for positive impact on global health challenges. [Online] Available: www.gbchealth.org

GBCHealth (2012). [Online] Available: www.gbchealth.org

GBCHealth (2011). [Online] Available: www.gbchealth.org 
Gray, B. (1989). Collaborating: Finding Common Ground for Multiparty Problems. San Francisco: Jossey-Bass.

Griffith, D. A., \& Harvey, M. G. (2001). Executive insights: An intercultural communication model for use in global inter-organizational networks. Journal of International Marketing, 9(3), 87-103. http://dx.doi.org/10.1509/jimk.9.3.87.19924

Hambrick, D. C., Li, J., Xin, K., \& Tsui, A. S. (2001). Compositional gaps and downward spirals in international joint venture management groups. Strategic Management Journal, 22, 1033-1053. http://dx.doi.org/10.1002/smj.195

Hood, J., Logsdon, J., Thompson, J., \& Kenner, J. (1993). Collaboration for social problem-solving: A process model. Business and Society, 1, 1-15. http://dx.doi.org/10.1177/000765039303200103

Kessler, R. C., Ames, M., Hymel, P. A., Loeppke, R., McKenas, D. K., Richling, D. E., Stang, P. E. ... (2004). Using the World Health Organization Health and Work Performance Questionnaire (HPQ) to Evaluate the Indirect Workplace Costs of Illness. Journal of Occupational and Environmental Medicine, 46(6), S23-S37. http://dx.doi.org/10.1097/01.jom.0000126683.75201.c5

Lawrence, C. (2002). Multi-and bi-lateral agencies to continue supporting public private partnership development. [Online] Available: http://www.ip3.org/publication2002_017.htm.

Leonard-Barton, D. A. (1990). A dual methodology for case studies: Synergistic use of a longitudinal single-site with replicated multiple sites. Organization Science, 1(3), 248-266.

Mitroff, I. I., Pearson, C. M., \& Harrington, L. K. (1996). The Essential Guide to Managing Corporate Crises. New York: Oxford University Press.

Nathan, M. L., \& Cummings, T. G. (1991). Fostering new university-industry relationships. In R. H. Kilmann (Ed.), Making Organizations Competitive. San Francisco: Jossey Bass.

Nathan, M. L., \& Kovoor-Misra, S. (2002). No pain, yet gain: Vicarious learning from crises in an inter-organizational field. Journal of Applied Behavioral Science, 38(2), 245-266. http://dx.doi.org/10.1177/00286302038002006

Nathan, M. L., \& Mitroff, I. I. (1991). The use of negotiated order theory as a tool for the analysis and development of an inter-organizational field. The Journal of Applied Behavioral Science, 27, 163-180. http://dx.doi.org/10.1177/0021886391272002

Nattrass, N., Neilson, T., Bery, P., \& Mistry, N. (2004). Opportunities for business in the fight against HIV/AIDS: A framework for analysis of the impact of HIV/AID on business and the benefits of direct company action in the global response. New York: Columbia University, University of Cape Town, Global Business Coalition.

Osborn, R. N., \& Hagedoorn, J. (1997). The institutionalization and evaluation of dynamics of inter-organizational alliances and networks. Academy of Management Journal, 261-278. http://dx.doi.org/10.2307/256883 


\section{Macrothink}

Case Studies in Business and Management

ISSN 2333-3324

2016, Vol. 3, No. 2

Ozcelik, H., Langton, N., \& Aldrich, H. (2008). Doing well and doing good: The relationship between leadership practices that facilitate a positive emotional climate and organizational performance. Journal of Managerial Psychology, 23(2), 186-203. http://dx.doi.org/10.1108/02683940810850817

Pesamaa, O. (2007). Development of relationships in inter-organizational networks: Studies in the tourism and construction industries. International Journal of Solids \& Structures.

Post, J., \& Waddock, S. (1989). Social cause partnerships and the "mega-event": Hunger, homelessness, and Hands across America. In F. Post (Ed.), Research in Corporate Social Performance and Policy, 11, 181-205. Greenwich, CT: JAI Press

Rosen, S., Simon, J., Vincent, J. R., MacLeod, W., Fox, M., \& Thea, D. M. (2003). AIDS is your business. Harvard Business Review.

Steiner, G. A., \& Steiner, J. F. (2003). Business, Government, and Society: A Managerial Perspective. New York: McGraw-Hill Irwin.

Turnbull, A., Parry, P., Gravestock, R., Guilford, Z., Clayton, P., Bery, P., Gorre, C. ... (2006). The State of Business and HIV/AIDS (2006): A Baseline Report. New York: Booz, Allen, Hamilton.

Wolf, K. (2010). Making the link between health and productivity at the workplace-a global perspective. Industrial Health, 48(3), 251-255. http://dx.doi.org/10.2486/indhealth.48.251

World Health Organization. (2002). New International Coalition aims to expand global access to HIV/AIDS treatment. Medical News Service.com.

World Health Organization. (2015). [Online] Available: www.who.org

UNAIDS (2004). Report on the global AIDS epidemic: Executive summary. The Joint United Nations Programme on HIV/AIDS.

UNAIDS (2014). [Online] Available: www.unaids.org

USAID (2014). [Online] Available: www.USAID.gov

\section{Copyright Disclaimer}

Copyright for this article is retained by the author(s), with first publication rights granted to the journal.

This is an open-access article distributed under the terms and conditions of the Creative Commons Attribution license (http://creativecommons.org/licenses/by/3.0/). 